\title{
A CONCEPTUAL FRAMEWORK FOR THE CENTER
}

\author{
GOING BEYOND SETTING PRIORITIES
}

\author{
Sally Kublenschmidt, Western Kentucky University \\ Susan Weaver, University of the Cumberlands \\ Susanne Morgan, Ithaca College
}

Management of faculty development centers can be made more effective and efficient by following a clearly articulated conceptual framework. This chapter examines three centers organized around distinct approaches. At one center, a single theme guides the choice of activities. At a second, primary faculty roles and organizational level of impact determine programming choices. At a third, a curriculum of teaching skills shapes planning and assessment. In each case, working from an explicit conceptual framework enables the center staff to more effectively prioritize competing demands and retain perspective in a changing higher education environment.

Faculty development centers often grow from some combination of the immediate needs of a particular institution, the strategic plan of the institution, and the particular talents of the director (Gillespie, Hilsen, \& Wadsworth, 2002). Typically, the center offers workshops, resources, consultation, and organizational engagement and may choose those activities simply on the basis of what other centers are doing (Hellyer $\&$ Boschmann, 1993) or on serendipity. In the ideal world, center staff advocate for faculty members to plan their curriculum around a coherent framework that is explicit to students. To what extent do faculty developers employ that same level of planning in the overall curriculum of center offerings and resources?

Center directors should be intellectually proactive. They should identify overall learning objectives for the entire program, develop a global 
approach that reflects those objectives, and then apply that approach to all decisions, from seminar selection to assessment priorities, from book purchasing to center database management. This chapter identifies the programmatic and administrative advantages of a conceptual framework for center management. Although some level of flexibility and responsiveness to the moment will always be necessary, deeper and long-term learning by faculty will best be accomplished if the staff has an intellectual basis for center offerings and daily choices.

The staff at three centers have started the process of structuring planning, activities, and assessment around a conceptual framework. After introducing the idea of a conceptual framework for center programs, we will review how each institution has begun to realize this goal. The three programs represent differing degrees of conceptual complexity. A small private college uses a single theme from which all activities and decisions follow. A medium-sized private comprehensive has devised a plan based on faculty role and organizational level of impact to decide what is critical for the institution. A large public comprehensive institution uses a curriculum to categorize, select, and assess activities. We recount the development of each institution's approach as well as the specifics of implementation, the assessment potential of the approach, and special issues for that particular approach.

\section{A Conceptual Framework}

As education specialists, faculty developers appreciate the value of objectives for advancing student learning. In a well-designed course the objectives direct selection of activities and the nature of assessments. Well-written objectives advance student motivation and help the instructor sustain interest and direct energies. At the end of the term, the success or failure of the course is judged against the learning objectives. Without learning objectives the instructor will waste time on nonproductive activities. Similarly, a faculty development center can benefit from a conceptually structured program to guide the focus of services. Hellyer and Boschmann (1993) approached the task of planning center actions by seeking normative data on what most centers did. However, a normative approach fails to match local needs, misses unique opportunities, and focuses on actions rather than learning outcomes. Cox (2001) proposed using faculty learning communities as a major center activity, arguing for the value of their intellectual power, an advantage of a conceptual framework. Without a guiding vision, the center ends up defined by others or implicitly self-defined as remediating or "preaching to the converted" 
(Chism \& Szabo, 1996). Everley and Smith (1996) point out that transitioning from soft to hard money works best when the center serves the values and goals of the institutional mission. Center staff need to make the institutional connection explicit as part of their planning process.

What is a conceptual framework? It is a coherent, selective vision relevant to the particular situation that guides the faculty development program over time and through changing trends. Although responsive to themes of current significance, a conceptual framework is grounded in research, best practice, or logical structures that are likely to endure. The goal of such a framework is meeting the long-term learning needs of the target population. It reflects truth, as currently understood, about what faculty members need.

A conceptual framework is not a laundry list of unrelated activities. It is not everything and anything that might fall within a description of a faculty development unit. Just as a theory that explains everything is useless, so too is an approach that fulfills every intellectual agenda. It is probably not simply a scaled-down version of the institution's strategic plan but a plan with center ownership.

Why adopt a conceptual framework in contrast to reacting only to external influences? Because moving toward a clear goal is a source of power. Having a framework grounded in what is researched or logically understood enables the unit to present a coherent plan to faculty and to persuade by ideas. A clear rationale for center activities enables the developer to think of the program as a whole and then identify parts that should be strengthened or abandoned. It invites complex assessments, such as appropriate balance among activities. It allows center staff to be proactive and thus drive conversation on campus. It enables more effective marketing and more persuasive arguments for resources. It also guides decisions about what direction not to pursue. A conceptual framework enables the center mission to absorb new ideas but still make progress on established ideas.

Of course, adopting a conceptual framework brings challenges. The most obvious one is how to create or select that framework. Who has the responsibility for choosing? Is it a leadership task for the director or a collaborative one for an advisory council? What factors should be considered in identifying the framework? How local should it be? How much of the larger society should it reflect? Will it be research-based or theoretical? Will it emphasize the ideal or the real?

Having a framework makes some aspects of center work easier. It eases directional decision making and sets a standard against which to measure decisions, from purchasing choices to the content of administrative 
reports. It should influence the content of center educational messages (for example, emphasizing critical thinking or technology) as well as their form (for instance, face-to-face seminars versus online workshops). At a minimum, a conceptual framework can lend coherence to center activities.

The relationship of the framework to the institution's goals is also important. If the framework diverges too much from those goals, the center staff will find itself at odds with administrative expectations and resources. If it overlaps with current institutional goals too much, it may lack the flexibility to adapt to changes in administrators who bring new interpretations of institutional goals. If nothing else, thinking through these issues prepares the center staff to respond more immediately and more substantively to queries and complaints. Having a conceptual framework means the unit has considered the institutional mission deeply and broadly and will be better prepared to deal with changing administrations-to retain what is critical to the unit and adapt to what is new and worthwhile.

\section{The Central Theme Approach: Critical Thinking Across the Curriculum}

The University of the Cumberlands is a private liberal arts college with about fifteen hundred undergraduate and eight hundred graduate students. The Center for Teaching and Learning (CTL) was established in August 2005 as part of the Quality Enhancement Plan (QEP) required for reaffirmation of accreditation by the Southern Association of Colleges and Schools. The CTL staff consists of a half-time administrative assistant and a full-time director who also serves as director of the QEP in cooperation with the QEP Steering Committee. The five-year QEP emphasizes critical thinking in reading and writing during the first two years, adding information literacy and oral communication in later years. The central organizing theme, Critical Thinking Across the Curriculum, grew out of two years of meetings with various stakeholders across campus.

Three mandates drive CTL programming. The first is to support faculty efforts to enhance critical thinking in the classroom. The second, in recognition that critical thinking involves both skills and dispositions (Leamnson, 1999), is to furnish cocurricular student programming that nurtures affective dispositions such as truth seeking and fair-mindedness (Facione, 1990). The third is to organize complementary professional development, including a summer retreat for a cadre of eight to ten faculty each year. Cadre members are charged with infusing their courses with critical thinking in reading, writing, oral communication, and information literacy, and then assessing their efforts. 
Although a few CTL programs are specifically for either faculty or students, most are open to faculty, staff, and students. Inclusiveness characterizes the campus culture and serves to increase the number of participants, enhance dynamics, and showcase efforts that incorporate critical thinking into areas of special interest and expertise. For example, every semester the CTL organizes a series of critical thinking seminars in which students and faculty discuss a chosen theme from among disciplinary perspectives. This semester, the subject of food is being examined from political, biological, health, and literary perspectives. Another example is an annual debate team event that features a short video about a controversial topic, followed by formal debate of the issue. In addition to reinforcing critical thinking as a campuswide initiative, these events promote networking that can lead to future collaborations or consultations.

ASSESSMENT OF THE APPROACH. Formative and summative assessments are built into the QEP plan. The CTL director uses feedback from the steering committee, workshop evaluations, email questionnaires, anonymous online surveys, focus groups, and informal communications to prepare an annual assessment report that reflects on the goals, outcomes, assessments, results, and recommendations. In addition, the university measures global success in advancing critical thinking through standardized testing of first-year students and juniors to track progress in reading, writing, and critical thinking.

The main difficulty in evaluating the Central Theme Model is isolating programming effects from confounding factors such as the students' natural transition from adolescence to young adulthood and their experience of living away from home, taking college classes, holding a job, or having new friends. Attendance and survey responses are suspect as measures because they are not direct assessments, and given a modest response rate the small student population yields a low number of responses. Further, even faculty who do not attend a workshop can spawn student reflection and growth. In reality, decisions to add or drop a program are based on best fit for the theme, stated needs and interests, or perceived needs.

CHALLENGES AND ISSUES. The theme affords the CTL name recognition and branding. The university's long-term commitment to critical thinking and the center's reputation for excellence make the Central Theme Model ideal. However, living up to varied expectations can be challenging, especially as the university establishes new programs and hires new faculty. As new needs and initiatives emerge, the director is tempted to overextend. On the other hand, the QEP mission plays heavily 
into development of these new programs and into assessment of the general education curriculum, thus granting the CTL security.

\section{Faculty Roles by Organizational Level Approach}

Ithaca College is a private comprehensive college with six thousand undergraduate and five hundred graduate students. Begun as a music conservatory, it has strong professional schools and liberal arts majors. Most of the $\mathbf{4 5 0}$ faculty members are full-time. The Center for Faculty Excellence (CFE) is a virtual center consisting of a webpage and activities implemented solely by a half-time faculty member.

Simply providing workshops to interested faculty was inefficient and ineffective in creating systemic change. Faculty perceived teaching as fundamental but expressed greater concern about accomplishing scholarship. The actions of department chairs and other leaders (Wergin, 2007) did not consistently reflect institutional priorities. The faculty culture varied dramatically from school to school, and institutional identity was weak.

Addressing these issues entailed systematic intervention focused on the roles in which faculty were required to succeed. Setting faculty roles by organizational level approach is designed to build a faculty of effective teachers, productive scholars, and engaged institutional citizens by supporting them at the individual, departmental, and institutional levels (see Table 2.1).

When previous CFE activities were mapped onto the table, it became clear that most were for individuals and focused on teaching, and few supported other areas. Now each event must fit in a cell, and the director monitors the grid to ensure impact on all faculty roles and at all levels. In place of the previous ad hoc workshops are structured public conversations about one of the three professional areas, scheduled on faculty request. Rather than the occasional faculty colloquium of the past, the CFE offers a half-day conference featuring faculty research in each of the faculty handbook's five types of scholarship, an important institutional concern. In addition, all faculty participating in key all-college programs

\section{Table 2.1. Choices in Faculty Development Activities}

Organizational Level

Faculty Role

Teaching

Scholarship

Service and citizenship

Individual Departmental Institutional 
must attend a four-day, year-end workshop themed around an institutional priority. At the department level, chairs now have their own series of events designed to increase the consistency and effectiveness of their work. Addressing the individual and institutional levels are two programs: a seminar for tenure-eligible faculty that supports their teaching, scholarship, and citizenship; and an all-college, group-based mentoring program, supplemented by departmental efforts, designed to create an institutionwide faculty culture.

ASSESSMENT OF THE APPROACH. The approach highlights a broad definition of faculty development and permits analysis of the institutional relevance of individual support. By categorizing activities in terms of the grid, a center that adopts this approach can quickly identify imbalances across cells and areas for further attention. It may discontinue some activities if too many occupy the same cell. Or it can reframe activities to serve at another organizational level. The grid can also facilitate conversation with administrators about expanding the center's mission to increase its organizational impact.

CHALLENGES AND ISSUES. This approach might suggest that a center be all things to all people-an unfeasible goal in a time of limited resources. However, the grid can inform reduction or redirection of services as well as expansion. For example, it guided the CFE's decision to discontinue ad hoc workshops and increase support for department chairs.

\section{The Curriculum Approach}

Western Kentucky University is a public master's-level institution with about nineteen thousand students. Its Faculty Center for Excellence in Teaching ( $\mathrm{FaCET}$ ) has been in existence about seventeen years and has a full-time staff of three, plus a part-time faculty associate and student workers. Its recent initiatives have addressed civic engagement and internationalism.

About six years ago the director became concerned that FaCET seminars were scattered in content and its programming might be overemphasizing some key aspects of instruction at the expense of others. So she devised a checklist of topics that the staff initially used for program assessment. The goal was to offer training, either a seminar or a print product, in each major area at least once during a three-year period. As part of a database overhaul, the staff decided to update the checklist and integrate it into the new database, devising a tool to qualitatively evaluate the depth and breadth of the program. 
The FaCET staff started from the existing checklist and added topics, developing a large number of themes. Then the professional staff plus two faculty associates individually sorted the themes into general categories. The group resolved discrepancies and revised categories until all members agreed the system contained essential, enduring components of instruction. The staff then took this curriculum to the FaCET faculty advisory council, which approved the system with very little discussion.

The system has seven major curricular areas, each with subcategories (the reporting protocol focuses on the major areas but uses the subcategories for some activities):

1. Understanding the student (major student variables or characteristics that influence learning; student diversity)

2. Teacher issues (career development issues; teaching assessment; special needs of faculty subgroups)

3. Preparing to teach (principles of effective teaching; learning basics; legal and ethical issues; course structuring; lesson structuring; class types)

4. Course in progress (active learning theory and methods; teaching methods; student behavior management; learning assessment; interdisciplinary content, such as writing)

5. Course technology (distributed education; technology applied to teaching)

6. Curriculum development (integrating courses with university and department objectives; managing outcomes)

7. Administrative experiences (academic leadership; departmental leadership; policies and procedures)

Staff members use the curriculum to plan FaCET programs and activities. Each event, resource item, and consultation is entered in the database within one of the seven categories. Individual faculty receive a report of their FaCET activities, called a Teaching Development Record. The seminars they attend are classified into the seven topic areas, showing the areas in which a faculty member was active or inactive. The goal of this reporting is to increase the complexity the faculty's and department heads' thinking about instruction. In planning the seminar schedule every year, FaCET staff members review the distribution of seminars across the seven categories with an eye on addressing each area over the set three-year period. Although university goals sometimes encourage heavy emphasis 
in one area for a year, the staff is able to restore balance in subsequent years. This planning process revealed that civic engagement activities did not fit into the curriculum, so the director gave up significant responsibility for a university civic engagement program.

The consultation data showed that FaCET staff members were doing a considerable amount of career planning with faculty. The data also made evident that a large number of the consultations fell in the category of course technology. This emphasis, along with faculty hiring trends, enabled the director to advocate successfully for a new position.

The database overall also presented the opportunity to bring more order and accessibility to the books, equipment, and other materials that had accumulated in the FaCET resource library. A skilled graduate student updated the library database and categorized all resources by the seven curricular areas. A report showed the neglected topics and guided later purchasing decisions. The database also enabled production of bibliographies for each area of resource. When the Teaching Development Records were mailed out, these bibliographies were offered to anyone wanting to find resources for an empty category.

ASSESSMENT OF THE APPROACH. FaCET staff members have found the curriculum approach to be a useful intellectual and administrative tool. It has given them a new perspective on activities and has allowed more precise planning and purchasing. Because they can compare the curriculum against the goals, acccuntability is inherent in the system. Review of the curriculum with each activity keeps these goals uppermost in staff thinking and offers a far more satisfying form of accountability than reporting seminar attendance or number of books checked out.

FaCET personnel are still exploring the potential of the curriculum approach. Beyond usage counts, they can track the content areas that appeal most and least to faculty and decide whether to offer more events and resources on popular topics or promote the neglected one. These data can then buttress requests for more resources in particular areas. They also allow the staff to compare the resources being provided with those the faculty want, and to customize activities accordingly. When faculty or administrators ask the center to organize an activity, the staff can compare activity to the curriculum to determine its appropriateness as a center project.

The greatest assessment limitation of this approach may be too much information, leading to difficulties interpreting the data and underuse of the data. In addition, if the curriculum fails to accommodate a new initiative, the available data may be useless for responding to that need. 
CHALLENGES AND ISSUES. Developing a locally relevant, well-structured curriculum takes time. Adopting an existing curriculum is easier and faster, but it may not meet local needs. The developers also have to keep in mind the durability of the curriculum. Can it incorporate current trends? Should it be designed for long-term or short-term goals? Another major issue is whom to involve in determining the curriculum. Although it is tempting to get input from advisory councils and administrators, perhaps even the whole faculty, this effort is simply not practical in many circumstances. Too much input can impede the process and produce a compromised curriculum. On the other hand, insufficient input can yield a curriculum that is divorced from real needs or tied too closely to an individual director's style.

The curriculum itself and how it is communicated can also help or hinder the project. If the curriculum is not easy to use and clear to all concerned parties, inconsistent implementation or conflicting understandings will doom the project. Although it may be tempting to incorporate every possible topic into the curriculum, no center can keep such broad promises. In addition, curricular categories must be consistent, reliable, mutually exclusive, and as simple as possible because new staff will have to be trained to use them.

The final challenge is addressing change. One reason to have a curriculum-based approach is to track changes in center activities over time. But change will come to the curriculum as well, interfering with that tracking. Ideally, a strong curriculum endures with minimal changes to permit long-term comparisons and trend mapping. The areas should be general enough to accommodate changes and minimize loss of long-term data. However, new presidential initiatives, major teaching innovations, and the like will eventually force restructuring of the curriculum.

\section{Conclusion}

Center staff wishing to adopt a conceptual framework will have to consider several factors. The approach chosen must fit within the overall campus strategic plan, which should in turn flow from the institutional mission. Accreditation expectations may also play a role in selecting an approach. The viability of the plan in the eyes of administrators and faculty is another consideration. If the approach is to be used beyond the confines of the center, then consider how it will appear to all constituencies and fit into campus culture. However, do not let fear of constituencies undermine the truth of the vision. In addition, the available resources and other constraints on center staff will influence which type of approach is selected. If only limited resources are available, then a more focused approach is desirable. 
If the clientele are diverse, then the approach needs to support them and may be correspondingly more layered.

Sometimes center staff may not have a choice in their approach. The specific conceptual framework may be chosen by another, and the center is expected to fulfill the initiative. In these cases, it may be possible to reconcile needs behind the scenes. For example, a center may have a twotiered approach. That is, it may have core concepts described with language unlikely to change (such as objectives, activities, and assessments) and then have a marketing approach laid over this deeper set of concepts (for example, civic engagement). The marketing approach may change for the sake of novelty and currency, but the staff understand what the deeper message is and infuse it into the surface idea.

Of course, a conceptual framework may become obsolete with time. New circumstances may call for a new theme, or the approach's language and concepts may not keep pace with changes in understanding. Center staff should review the framework regularly and adapt it as necessary. Finally, a strategy for assessing the approach requires advance planning. How will a director know if the approach is working for the center? How well is it meeting the goals and needs of the unit? What are the criteria for success? The fact that the approach must change eventually does not invalidate its usefulness for the next five to ten years, or even longer.

Whether a center's framework is based on one of the approaches outlined in this chapter, is a hybrid, or is grown from local needs, working from an explicit conceptual framework imparts a structure that offers perspective and prioritizing for daily activities and a strong mission for long-term success.

\section{REFERENCES}

Chism, N.V.N., \& Szabo, B. (1996). Who uses faculty development services? In L. Richlin \& D. DeZure (Eds.), To improve the academy: Vol. 15. Resources for faculty, instructional, and organizational development (pp. 115-128). Stillwater, OK: New Forums Press.

Cox, M. (2001). Faculty learning communities: Change agents for transforming institutions into learning organizations. In D. Lieberman \& C. Wehlburg (Eds.), To improve the academy: Vol. 19. Resources for faculty, instructional, and organizational development (pp. 69-93). Bolton, MA: Anker.

Everley, M. L., \& Smith, J. (1996). Making the transition from soft to hard funding: The politics of institutionalizing instructional development programs. In L. Richlin \& D. DeZure (Eds.), To improve the academy: Vol. 15. Resources for faculty, instructional, and organizational development (pp. 209-230). Stillwater, OK: New Forums Press. 
Facione, P. (1990). Critical thinking: A statement of expert consensus for purposes of educational assessment and instruction. Millbrae, CA: California Academic Press.

Gillespie, K. H., Hilsen, L. R., \& Wadsworth, E. C. (Eds.). (2002). A guide to faculty development: Practical advice, examples, and resources. Bolton, MA: Anker.

Hellyer, S., \& Boschmann, E. (1993). Faculty development programs: A perspective. In D. L. Wright \& J. P. Lunde (Eds.), To improve the academy: Vol. 12. Resources for faculty, instructional, and organizational development (pp. 217-224). Stillwater, OK: New Forums Press.

Leamnson, R. (1999). Thinking about teaching and learning: Developing habits of learning with first year college and university students. Sterling, VA: Stylus.

Wergin, J. F. (Ed.). (2007). Leadership in place: How academic professionals can find their leadership voice. Bolton, MA: Anker. 